
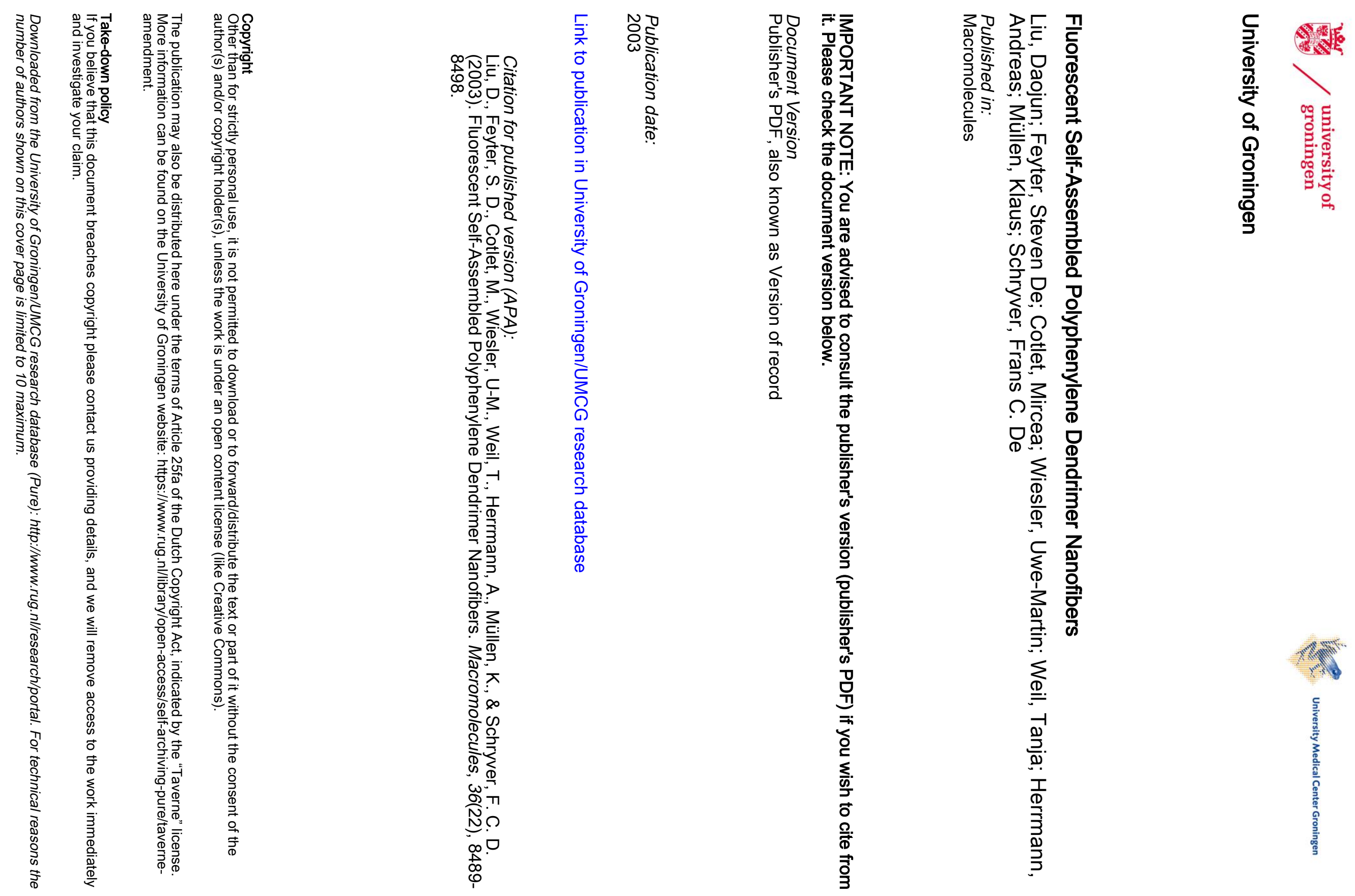

i㝏

กำ

\D.

응 후

꼬욤

心ミ

○吕

به

$\leq 2$

品 극.

Ф

¿

市 음

$\equiv$

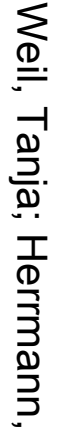

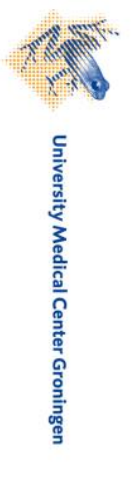




\title{
Fluorescent Self-Assembled Polyphenylene Dendrimer Nanofibers
}

\author{
Daojun Liu, ${ }^{\dagger}$ Steven De Feyter, ${ }^{*}, \dagger$ Mircea Cotlet, ${ }^{\dagger}$ Uwe-Martin Wiesler, ${ }^{\ddagger}$ \\ Tanja Weil, ${ }^{\ddagger}$ Andreas Herrmann, ${ }^{\ddagger}$ Klaus Muillen, ${ }^{\ddagger}$ and Frans C. De Schryver, ${ }^{* \dagger}$
}

Laboratory for Photochemistry and Spectroscopy, Department of Chemistry, Katholieke Universiteit Leuven (KULeuven), Celestijnenlaan 200F, B-3001 Leuven, Belgium, and Max Planck Institute for Polymer Research, Ackermannweg 10, 55128 Mainz, Germany

Received June 24, 2003

\begin{abstract}
A second-generation polyphenylene dendrimer 1 self-assembles into nanofibers on various substrates such as HOPG, silicon, glass, and mica from different solvents. The investigation with noncontact atomic force microscopy (NCAFM) and scanning electron microscopy (SEM) shows that the morphology of the dendrimer nanofibers highly depends on substrate, solvent, and preparation method. Fluorescent nanofibers can be prepared from a polyphenylene dendrimer with chromophores either attached to the periphery of the dendrimer or incorporated in its core. Fluorescent nanofibers formed from polyphenylene dendrimer $\mathbf{4}$ with a perylenediimide core show isolated-chromophore emission due to the shielding of the rigid polyphenylene dendrons. Dendrimer 2 with one perylenemonoimide attached toits periphery self-assembles intofluorescent nanofibers, which exhibit a dimer like emission as a result of the interactions between peripheral chromophores. Dendrimer $\mathbf{3}$ with two perylenemonoimides at the rim does not form nanofibers by itself, but mixing of nonfluorescent dendrimer $\mathbf{1}$ with fluorescent dendrimers 2 or 3 leads tothe formation of nanofibers with a homogeneous composition. Therefore, mixing can not only coassemble nonnanofiber-forming dendrimer 3 intonanofibers but also give rise to isolatedchromophore emission upon proper dilution.
\end{abstract}

\section{Introduction}

Dendrimers have attracted much attention for the past two decades because of their fascinating structure and unique properties such as their globular shape, highly controlled size, radially controlled chemical composition, multivalent periphery, and variable inner volume. ${ }^{1-4}$ Self-assembly of dendrimers with or without guest molecules at the ensemble ${ }^{5-10}$ as well as the single molecule level ${ }^{11}$ is of special interest because this creates a wide collection of novel structures and surfaces with higher complexity and promising properties.

The self-assembly of dendrimers into mono- or multilayers on a solid substrate through electrostatic interactions, ${ }^{12-16}$ polydentate interactions, ${ }^{17-21}$ or covalent bonding 22 has been investigated. The self-assembled dendrimer mono- or multilayers were found to exhibit unique properties and potential applications such as their use as nanoreservoirs, ${ }^{15}$ as moleaular gate membranes, ${ }^{17 a}$ and as effective resists for high-resolution lithography. ${ }^{23}$ With the techniques of microcontact printing $(\mu \mathrm{CP})$ and dip-pen nanolithography, dendrimer molecules have been patterned on a substrate surface, ${ }^{23-25}$ which also allows the subsequent postfunctionalization for the fabrication of patterned nanostructures.

Dendrimers can also self-assemble into three-dimensional nanostructures. Tomalia and co-workers ${ }^{26}$ have reported the self-assembly of PAMAM dendrimers into supramolecular core-shell dendrimer assemblies with higher complexity and dimensions. Percec and coworkers ${ }^{27}$ have reported the self-assembly of monodendritic building blocks in bulk into spherical, cylindrical,

* Correspanding authors: e-mail steven.defeyter@dhem.kuleuven. ac.be or frans.deSchryver@chem.kuleuven.ac.be; Fax (+32)-16 327989.

${ }^{\dagger}$ Laboratory for Photochemistry and Spectroscopy.

‡ Max Planck Institute for Polymer Research. and more complex supramolecular and supramacromolecular dendrimers. Masuhara ${ }^{28}$ and Schlüter 29 also investigated self-assembled nanostructures from dendronized polymers, a type of dendrimer with multiple functional polymer cores.

Lamellar patterns formed via the side-by-side arrangement of linear polyphenylenes ${ }^{30}$ and columns built from face-to-face polycydic aromatic hydrocarbons (PAHs) due to the $\pi-\pi$ interactions ${ }^{31}$ have been described as typical supramolecular patterns of benzene-based macromolecules. Polyphenylene dendrimers are a special class of dendrimers, 3,32 which are characterized by their shape-persistent 3D structures. ${ }^{33,34}$ Polyphenylene dendrimers have been observed to form several hundred nanometer long organized structures when additional alkyl chains are attached to their periphery ${ }^{35}$ as well as dendrimer multilayers with gold nanoparticles. ${ }^{20}$

We have recently reported that polyphenylene dendrimers with various cores (such as tetraphenylmethane, biphenyl, and azobenzene) and of different generations can self-assemble into micrometer long nanofibers in addition to the formation of globular dendrimer aggregates, on hydrophobic surfaces such as HOPG and silanized mica. ${ }^{36} \mathrm{~A}$ special case is dendrimer 1 (Figure 1), a second-generation polyphenylene dendrimer containing a tetraphenylmethane core, which exclusively self-assembles into micrometer long nanofibers by drop-casting under controlled atmospheric conditions. A critical issue is the extent to which the polyphenylene dendrimers can be functionalized while still retaining their fiber-forming properties. What is the effect of modifying the dendrimer core? Will the dendrimers decorated at the rim with one or multiple functionalities still can form nanofibers? In this contribution, we investigate the effect of solvent, substrate, and controlled atmospheric conditions on the formation and morphology of the nanofibers. To get insight into the effect of functionalization, we have investigated the 


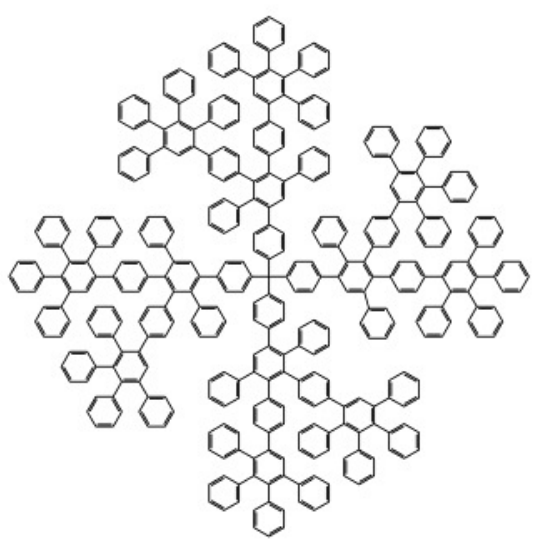

1a

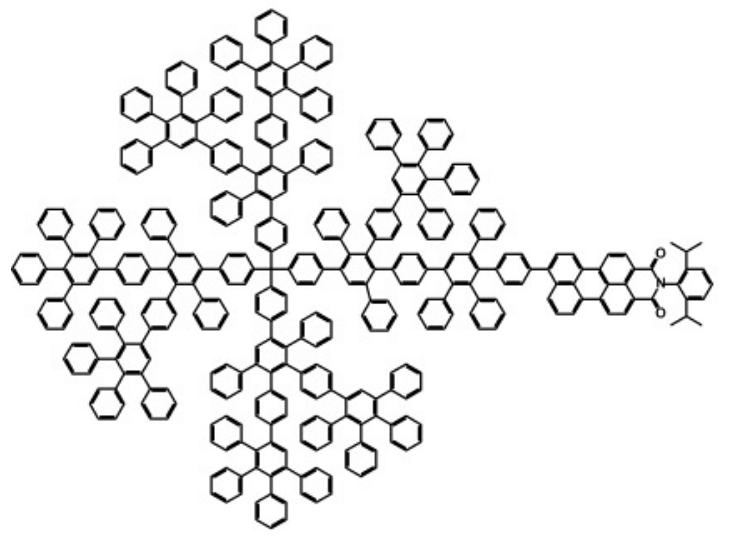

2
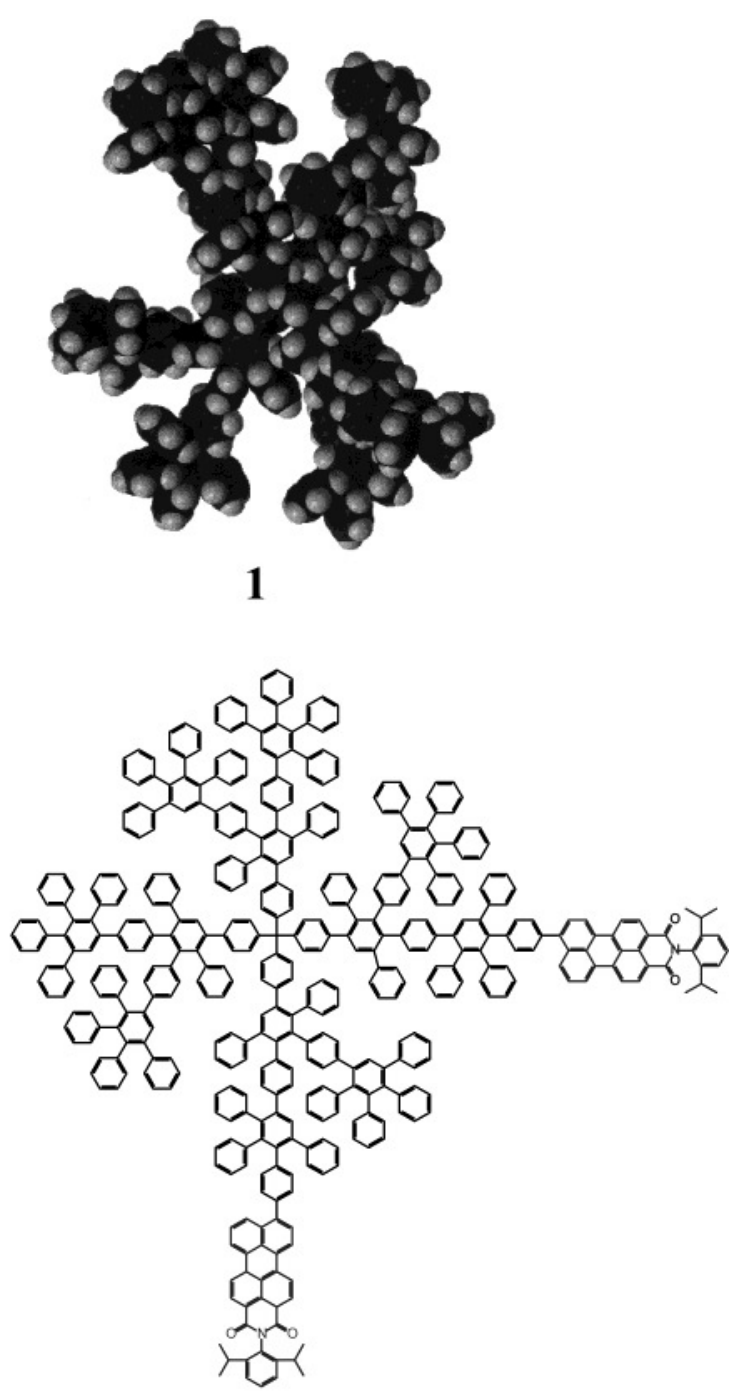

3

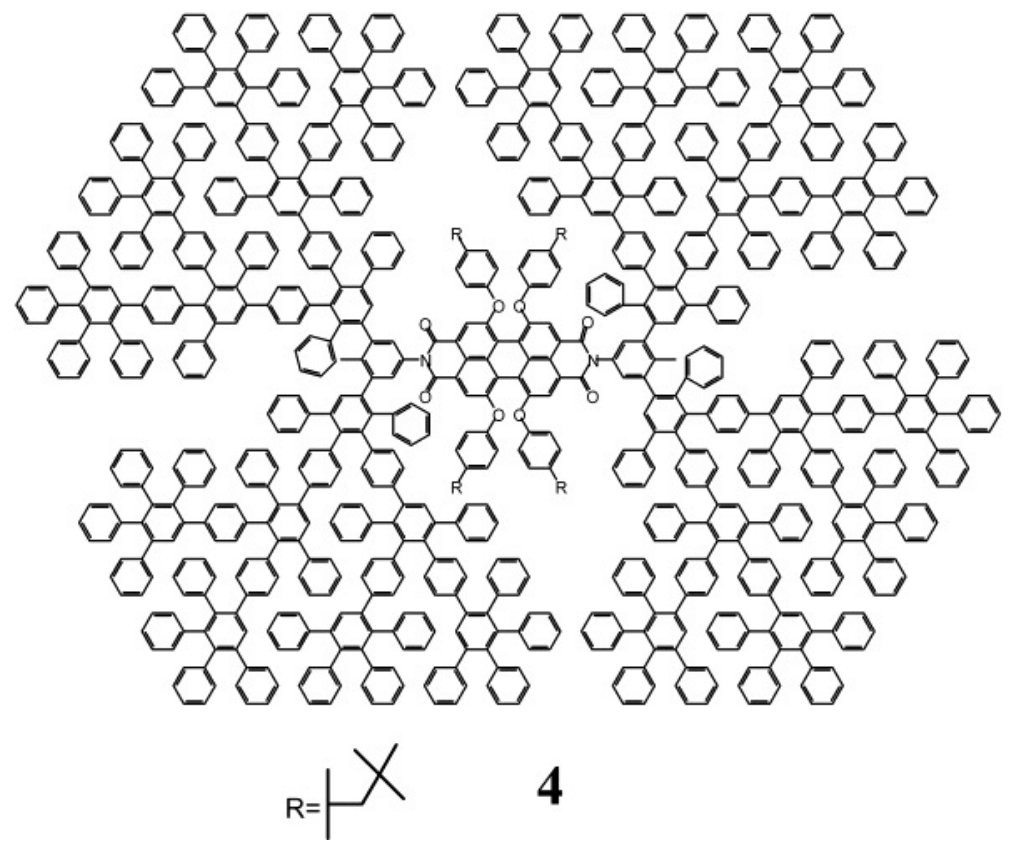

Figure 1. (1a) Molecular structure of polyphenylene dendrimer 1. (1b) Space-filling view of dendrimer 1 built by a Merck Molecular Force Field (MMFF) method. (2, 3) Molecular structures of polyphenylene dendrimers with perylenemonoimide attached to the periphery. (4) Molecular structure of polyphenylene dendrimer with a perylenediimide core. 
self-assembly properties of dendrimers functionalized with one or multiple fluorescent peryleneimide chromophores. We have explored the influence of the number and location of the chromophore(s) within the dendrimer and the effect of mixing with nonfunctionalized dendrimers.

\section{Experimental Section}

Chemicals. The synthesis of polyphenylene dendrimers 1-4 has already been reported. ${ }^{32,37,38}$ These dendrimers exhibit good solubility in common organic solvents and thus can be characterized by MALDI-TOF-MS. The perfect agreement between calculated and experimentally determined $\mathrm{m} / \mathrm{s}$ ratios confirms its monodispersity. $\mathrm{CHCl}_{3}$ (Acros Organics, Fair Lawn, NJ), THF (Acros Organics, Fair Lawn, NJ), acetone (Aldrich Chemical Co. Inc., Milwaukee, M), and ethanol (BDH Laboratory Suppliers, Poole, England) were used as received. All the used solvents are of spectrophotometric grade.

Substrates. The HOPG and mica were freshly cleaved immediately before use. The glass and silicon substrates, which have an oxide layer of several nanometers, were pretreated for $10 \mathrm{~min}$ in an ultrasonic bath at $25^{\circ} \mathrm{C}$ in acetone and then cleaned in a piranha solution (7:3 mixture of concentrated sulfuric acid and 30\% hydrogen peroxide) at 70 ${ }^{\circ} \mathrm{C}$ for $30 \mathrm{~min}$. After the treatment, the substrate was thoroughly rinsed with Milli-Qwater and blow-dried with nitrogen.

Sample Preparation. Assemblies of dendrimers were prepared on the surface of substrates by drop casting. Briefly, a substrate was put in a nearly closed glass container $(20 \mathrm{~cm}$ $\times 8 \mathrm{~cm} \times 20 \mathrm{~cm}$ ) with preadded organic solvent (or mixture of water and organic solvent) in order to create a saturated solvent enviranment. Then five drops (ca. $150 \mu \mathrm{L}$ ) of dendrimer solution (see figure captions for concentrations of dendrimer solutions) were deposited on the surface of substrate. The solvent evaporated slowly, typically within several hours, depending on the specific solvent.

Atomic Force Microscopy (AFM). Assemblies of polyphe nylene dendrimers were visualized with AFM. AFM was performed with a Discoverer TMX201O AFM system (ThermoMicroscopes, San Francisco, CA) operating in noncontact mode using Si probes (ThermoMicroscopes, San Francisco, CA) with a spring constant of 34-47 N/m and a resonance frequency of $174-191 \mathrm{kHz}$. A calibration silicon grating (TGZO1, pitch $3 \mu \mathrm{m}, \Delta \boldsymbol{z}=26 \pm 1 \mathrm{~nm}$, MicroMasch, Tallinn, Estonia) was used to calibrate the piezo scanner. Measurements were done under ambient conditions. Image analysis was performed with Topometrix SPMLab 5.O.

Scanning Electron microscope (SEM). Assemblies of dendrimer $\mathbf{1}$ on the silicon substrate were also visualized with a SEM (JEOL TSM-5600). SEM was performed with an acceleration voltage of $15 \mathrm{kV}$ and, in a few cases, at a tilted angle.

Confocal Fluorescence Microscopy. Picosecond timeresolved confocal fluorescence detection and spectroscopy from dendrimer nanostructures was performed using an optical setup that is described elsewhere. ${ }^{39}$ Briefly, samples on a silicon substrate were mounted on an Olympus IX 7Oinverted microscope equipped with a scanning stage (Physics Instruments, Waldbrown, Germany). Excitation with the $488 \mathrm{~nm}$ pulsed laser line, achieved by frequency-doubling the output of a mode-locked picosecond Ti:sapphire laser (Tsunami Spectra Physics) pumped by an $\mathrm{Ar}^{+}$laser (BeamLok 2080Spectra Physics), occurred through a dry objective lens (0.85NA, $\times 63$, Zeiss). Fluorescence was collected by the same objective, passed through a dichroic mirror (DRLP495Chroma Technology, Brattleboro, NY), filtered through a notch filter (Kaiser Optical Systems, Ann Arbor, MI), and simultaneously focused, via a $50 \mu \mathrm{m}$ pinhole and a 50-50\% nonpolarizing beam splitter cube, on an avalanche photodiode (APD) (SPCM 15, EG \& G, Quebec) and into the entrance of a polychromator (Acton SP 150) coupled to a cooled charge-coupled device camera (Princeton Instruments). The signal from the APD was input into a time-correlated single photon counting PC card (SPC 630,
Picoquant $\mathrm{GmbH}$ ). The fluorescence decays were analyzed with a homemade program that uses a reweighted iterative reconvolution method based on the Marquard algorithm. The goodness of the fits were judged by the values of the reduced $\chi^{2}$ as well as by inspecting the residual function graphs for each fitted data set.

Molecular Modeling. Geometry optimization of the dendrimer 1 was performed in a vacuum by a molecular mechanics method (Merck Molecular Force Field) ${ }^{40}$ in Spartan (Wave Function Inc., Irvine, CA).

\section{Results and Discussion}

Self-Assembled Polyphenylene Dendrimer 1 Nanofibers on Various Substrates. We have shown in previous papers ${ }^{36}$ that polyphenylene dendrimers with a well-defined 3D structure can self-assemble into fibrillar nanostructures. Most of these polyphenylene dendrimers self-assemble into micrometer long nanofibers, along with the formation of globular dendrimer aggregates, on a hydrophobic surface such as a HOPG or silanized mica. In this section, we explore the effect of deposition conditions and substrate properties on the formation of self-assembled structures by dendrimer $\mathbf{1}$, of which we have demonstrated the formation of nanofibers under controlled conditions previously. ${ }^{36 b}$

Figure 2A shows a representative AFM image of nanofibers formed from dendrimer $\mathbf{1}$ by drop-casting from a $\mathrm{CHCl}_{3}$ solution on a HOPG surface. Dendrimer 1 exclusively self-assembles intofibrillar nanostructures under controlled atmospheric conditions (see Experimental Section). In addition to the formation of discrete nanofibers, most of the nanofibers aggregate into bundles forming clusters (Figure $2 \mathrm{~B}$ ). The length of the nanofibers is typically less than $10 \mu \mathrm{m}$. On a silicon surface, bigger nanofiber clusters composed of nanofibers with a length of tens of micrometers were obtained. The diameter of these clusters ranges from 10 to $200 \mu \mathrm{m}$ as revealed by AFM and SEM measurements. Typical AFM and SEM images of a dendrimer 1 nanofiber duster on a silicon surface are shown in parts $C$ and $D$ of Figure 2 respectively.

The ordering of nanofibers intoclusters is considered to be the result of dewetting. Because of the dewetting in the course of the evaporation process, the dendrimer solution evolves into separated domains, ${ }^{41}$ within which the nanofibers form and aggregate into clusters. The area around the nanofiber cluster in Figure $\mathrm{C}$ is almost free of dendrimer molecules. Because of the difficulty of preparing a mesoscale flat HOPG surface by deaving and the presence of numerous steps and kinks over large dimensions, the HOPG surface should be rougher than that of the silicon. This could lead to the formation of smaller and more domains of droplets of dendrimer in solution at the HOPG surface toward the end of the solvent evaporation, which could explain the fact that smaller and more dendrimer nanofiber clusters as well as discrete nanofibers are formed on the surface of HOPG compared to a silicon surface (Figure 2A,C).

When THF was used as the solvent, the nanofibers prepared by drop-casting on a silicon surface were observed to be quite evenly distributed, and they formed a network extending over the entire substrate surface. A representative AFMimage of a dendrimer 1 nanofiber network formed under such experimental conditions is shown in Figure 3A. There is substantial aggregation of the dendrimer nanofibers into nanofiber bundles (Figure 3B). The rather homogeneous distribution of the nanofibers formed from THF solution on the silicon 

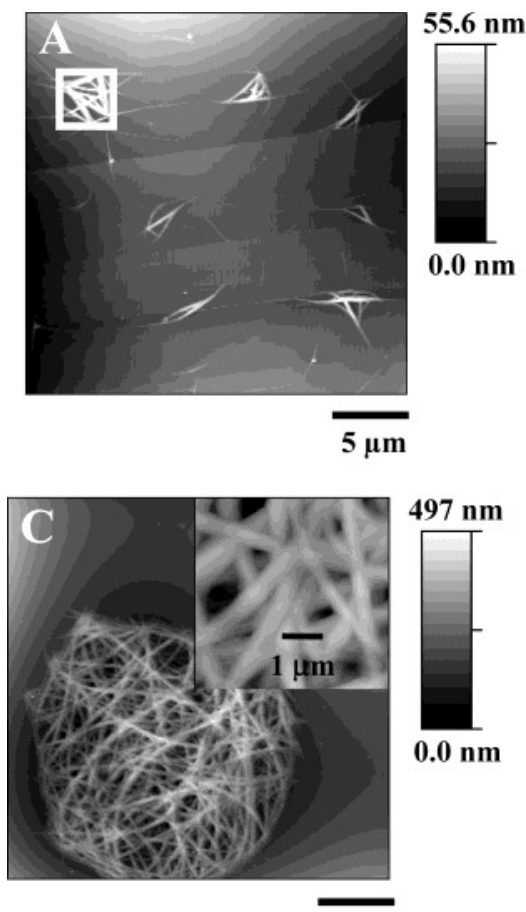

$10 \mu \mathrm{m}$
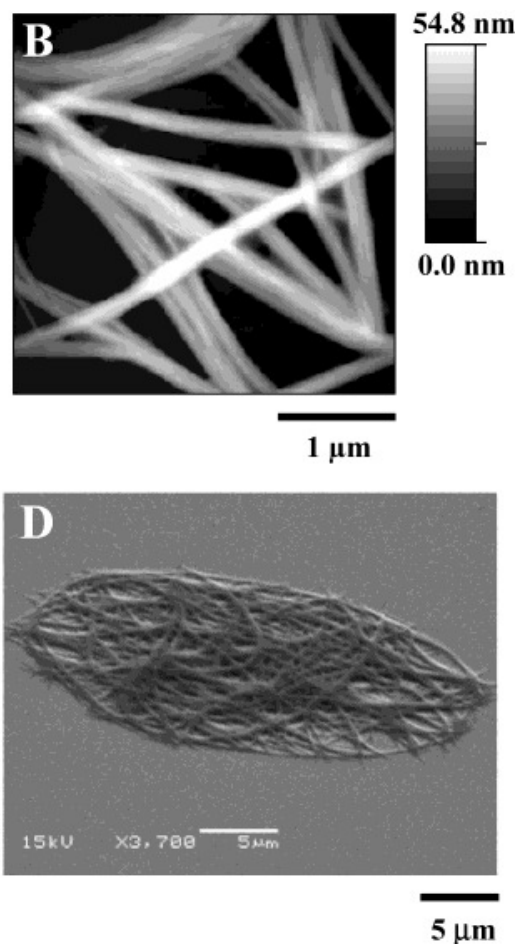

Figure 2 (A) NCAFM image $(25 \mu \mathrm{m} \times 25 \mu \mathrm{m})$ of dendrimer 1 nanofibers prepared by drop-casting a $1 . \mathrm{O} \times 1 \mathrm{O}^{-5} \mathrm{M}$ dendrimer $\mathbf{1}$ solution in $\mathrm{CHCl}_{3}$ on a HOPG surface. (B) A smaller scale NCAFM image $(3.5 \mu \mathrm{m} \times 3.5 \mu \mathrm{m})$ of a dendrimer 1 nanofiber cluster in part A indicated by a frame. (C) NCAFM image $(50 \mu \mathrm{m} \times 50 \mu \mathrm{m})$ of a dendrimer 1 nanofiber cluster prepared by drop-casting a $1 . \mathrm{O} \times 1 \mathrm{O}^{-5} \mathrm{M}$ dendrimer 1 solution in $\mathrm{CHCl}_{3}$ on a silicon surface. A smaller scale AFM image $(5 \mu \mathrm{m} \times 5 \mu \mathrm{m})$ is shown in the inset. (D) SEM image of a dendrimer $\mathbf{1}$ nanofiber cluster on a silicon surface imaged at a tilted angle of $70^{\circ}$.

surface could be ascribed to the improved wetting properties of THF toward the oxidized silicon surface, which results in a thin dendrimer solution layer rather than separated domains at the final stage of the solvent evaporation.

It was found that the addition of a small amount of water to the THF atmosphere during the drop-casting suppressed the aggregation of nanofibers. Parts $C$ and $\mathrm{D}$ of Figure 3 show AFM images of the nanofibers formed from a dendrimer $\mathbf{1}$ solution in $\mathrm{THF}$ in a saturated atmosphere of THF and 5\% and 10\% (v $x)$ $\mathrm{H}_{2} \mathrm{O}$, respectively. In the presence of $10 \%$ water, a large number of individual aurved nanofibers is obtained with many crossing points (Figure $\mathrm{E}, \mathrm{F}$ ). The topography profile in Figure $\mathrm{Z}$ s shows that the nanofibers formed have a height of tens of nanometers. Since water can completely wet the oxidized silicon surface, the presence of water will certainly improve the wetting properties of the mixed solvent with $\mathrm{THF}$ and thus decrease the shear force of the lateral flow of the solvent. This might explain why less aggregated dendrimer nanofiber bundles are observed with increasing amount of water (Figure 3A,C,D). Upon increasing the water content in the mixed solvent atmosphere to $20 \%$, straighter nanofibers were obtained, which evolve into "star"-shaped networks, as indicated by the AFM and SEM images in Figure 3G-I. The SEM image in Figure 3 shows that the nanofibers are still well-separated even in the center of the "star", suggesting that the nanofiber networks did not grow divergently from the center but were formed as a result of the convergent aligning of the preformed nanofibers.

The morphology of the nanofibers formed by dropcasting a dendrimer $\mathbf{1}$ solution in THF on a silicon surface was also dependent on the water content in the mixed vapor atmosphere. With less than $10 \%$ water, the nanofibers have a round cross section (Figure 3B). With increasing water content, the surfaces of nanofibers become more flat, as indicated by the topography profile in Figure $3 \mathrm{E}$ ( $10 \%$ water). When the water content was increased to $20 \%$, nanoribbons with a flat surface were dearly observed as reported in Figure $3 \mathrm{H}$ and the related topography profile. Some nanoribbons are tilted relative to the substrate surface. Comparison between the dimensions of these nanofibers obtained by AFM and SEM supports the formation of nanoribbons. As can be seen from the topography profiles in Figure $3 \mathrm{H}$, the height of the nanoribbons is typically less than $100 \mathrm{~nm}$, whereas the width of the nanoribbons presented in Figure 3I is around $200 \mathrm{~nm}$. Increasing further the water content to about $40 \%$ results in an irreproducible nanofiber structure. Above $40 \%$ water content, only globular aggregates of dendrimer $\mathbf{1}$ were observed as a result of the rapid evaporation of THF. The globular aggregates formed from dendrimer 1 solution in THF in a pure water vapor environment are shown in Figure 3J.

It should be pointed out that since the glass and mica substrates have similar surface properties as silicon, the formation of nanofiber networks of dendrimer $\mathbf{1}$ on these two substrates was also observed, and representative AFM images are shown in parts $A$ and $B$ of Figure 4, respectively.

Formation of Fluorescent Nanofibers from Functionalized Polyphenylene Dendrimers. (A) SelfAssembly of Monochromophoric and Multichromophoric Dendrimers. Dendrimer 2 only differs from dendrimer $\mathbf{1}$ in the presence of a perylenemonoimide chromophore covalently linked to the polyphenylene arms of the dendrimer periphery. It was hoped that the attachment of this chromophore would not influence the self-assembling behavior too much as dendrimer $\mathbf{1}$ has 

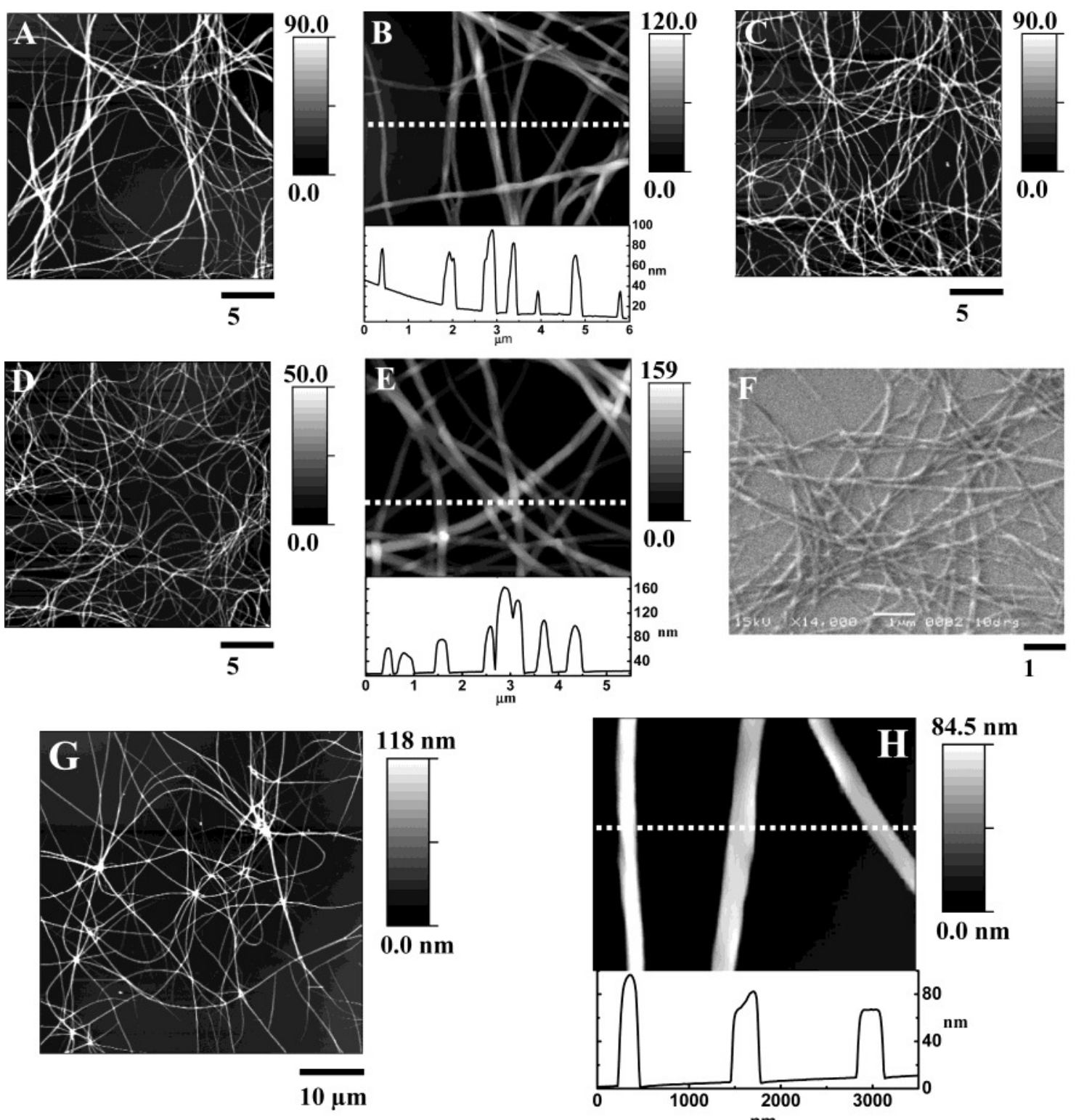

$84.5 \mathrm{~nm}$

$0.0 \mathrm{~nm}$
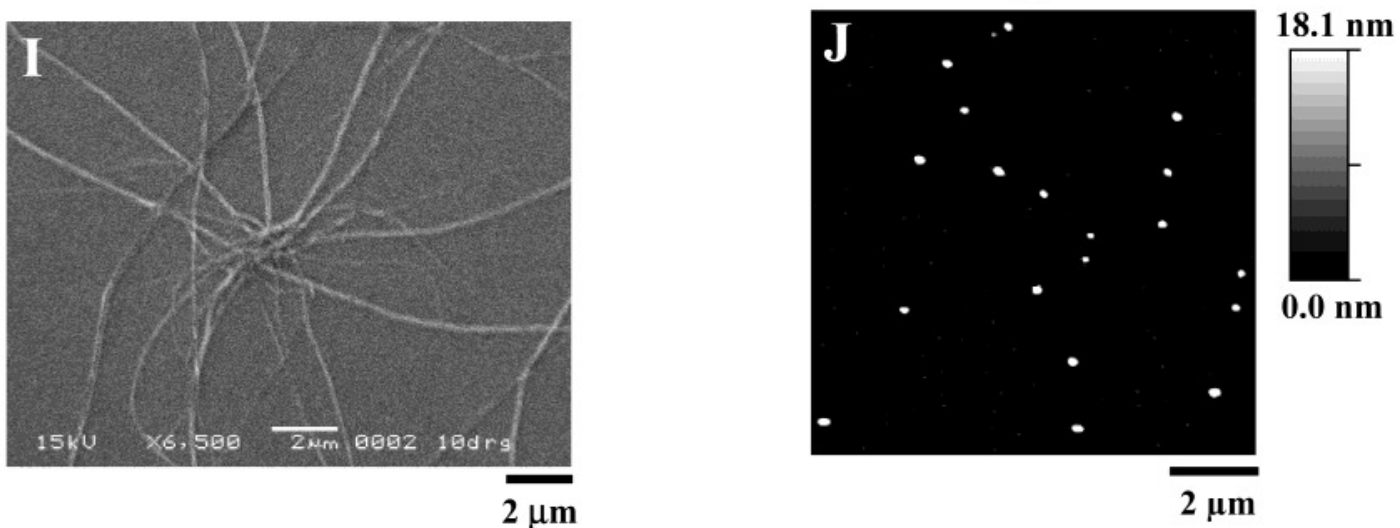

Figure 3. (A) NCAFM image $(25 \mu \mathrm{m} \times 25 \mu \mathrm{m})$ of dendrimer 1 nanofibers prepared by drop-casting a $20 \times 10^{-6} \mathrm{M}$ dendrimer $\mathbf{1}$ solution in THF on a silicon surface in a saturated environment of THF. (B) A smaller scale NCAFM image of part A. Topography profile along the dotted line indicated in the image is shown beneath. (C) NCAFMimage $(25 \mu \mathrm{m} \times 25 \mu \mathrm{m})$ of dendrimer 1 nanofibers prepared by drop-casting a $2 \mathrm{O} \times 10^{-6} \mathrm{M}$ dendrimer 1 solution in THF in a saturated environment of THF: $\mathrm{H}_{2} \mathrm{O}=95: 5(\mathrm{v} x)$ on a silicon surface. (D) NCAFM image $(25 \mu \mathrm{m} \times 25 \mu \mathrm{m})$ of dendrimer 1 nanofibers prepared by drop-casting a $2 \mathrm{O} \times 10^{-6} \mathrm{Mdendrimer}$ 1 solution in THF in a saturated environment of THF: $\mathrm{H}_{2} \mathrm{O}=90.10(\mathrm{v} x)$ on a silican surface. (E) A smaller scale NCAFM image of part D. Topography profile along the dotted line indicated in the image is shown beneath. (F) SEM image of part D. (G) NCAFM image $(50 \mu \mathrm{m} \times 50 \mu \mathrm{m})$ of dendrimer 1 nanofibers prepared by drop-casting a $2 \mathrm{O} \times 10^{-6} \mathrm{M}$ dendrimer 1 solution in THF in a saturated environment of THF: $\mathrm{H}_{2} \mathrm{O}=80.20(\mathrm{v} x)$ on a silicon surface. $(\mathrm{H})$ A smaller scale NCAFM image of part $\mathrm{G}$. Topography profile along the dotted line indicated in the image is shown beneath. (I) SEM image of part G. (J) NCAFM image (1O $\mu \mathrm{m} \times 1 \mathrm{O}$ $\mu \mathrm{m}$ ) of dendrimer 1 aggregates prepared by drop-casting a $2 \mathrm{O} \times 10^{-6} \mathrm{M}$ dendrimer 1 solution in $\mathrm{THF}$ at a saturated $\mathrm{H}_{2} \mathrm{O}$ environment on a silicon surface. 

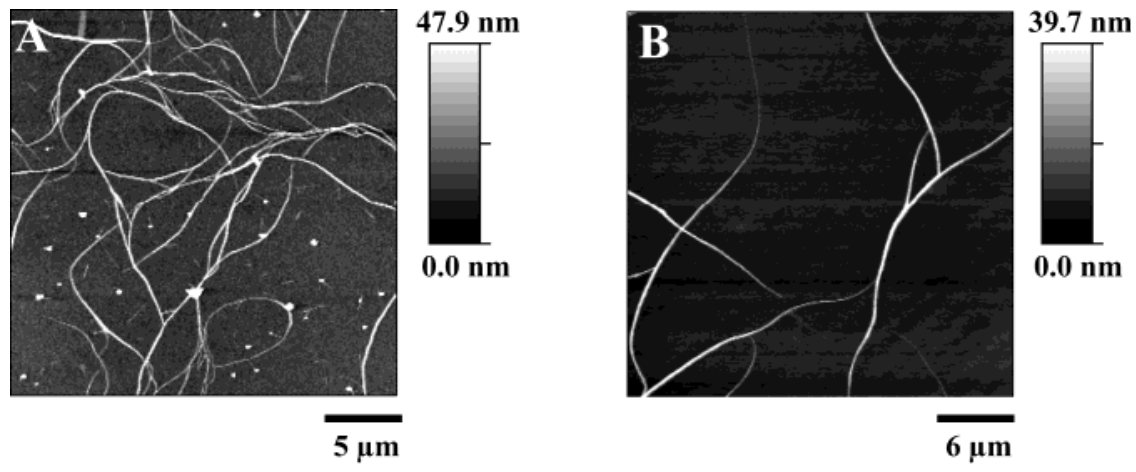

Figure 4. NCAFM image of dendrimer 1 nanofibers prepared by drop-casting a $2 \mathrm{O} \times 1 \mathrm{O}^{-6} \mathrm{M}$ dendrimer 1 solution in THF in a saturated environment of $\mathrm{THF}: \mathrm{H}_{2} \mathrm{O}=90.10(\mathrm{v} x)$ on a glass surface $(\mathrm{A}, 25 \mu \mathrm{m} \times 25 \mu \mathrm{m})$ and on a mica surface $(\mathrm{B}, 30 \mu \mathrm{m} \times 30 \mu \mathrm{m})$.
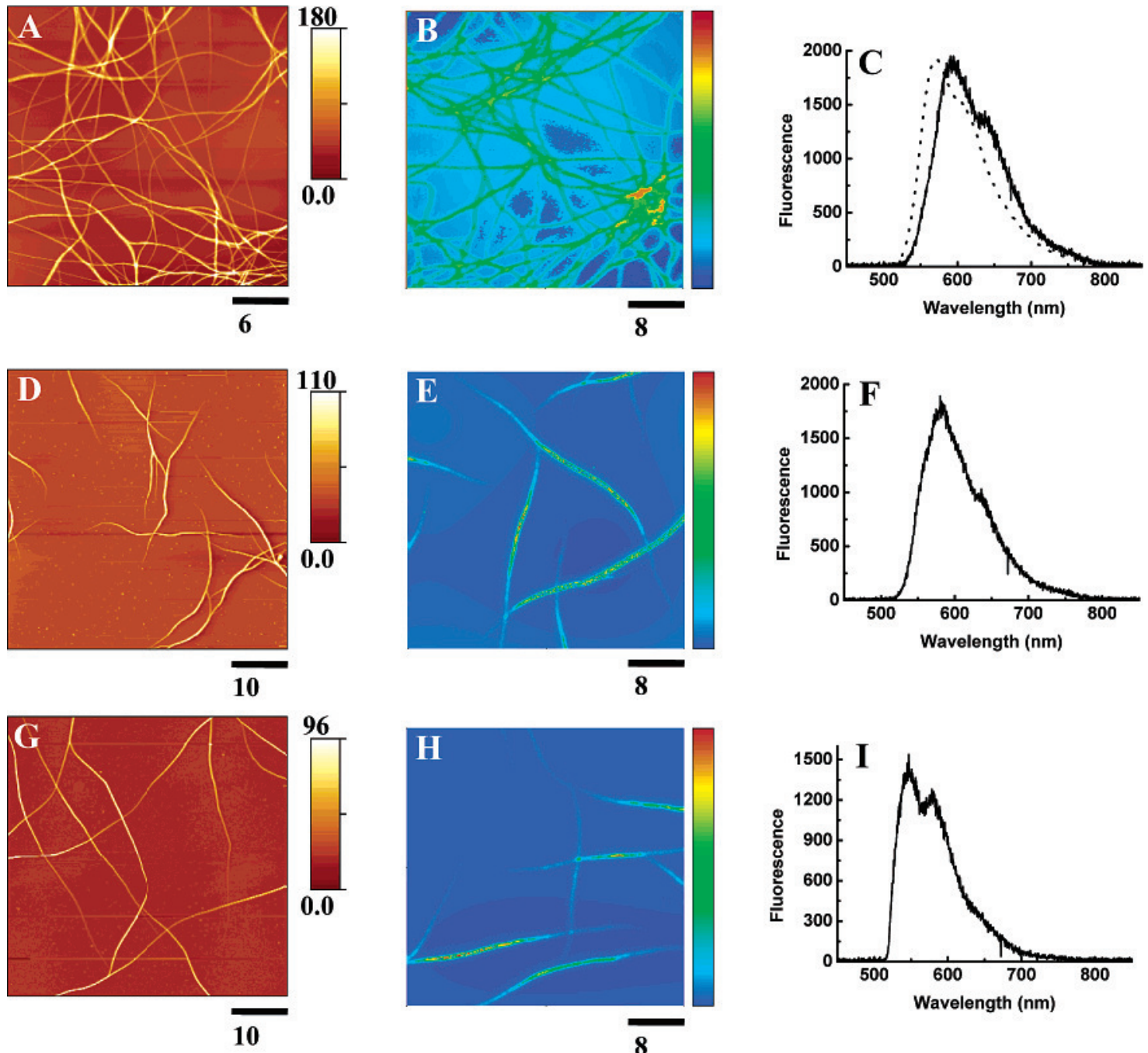

Figure 5. NCAFM image (A, $30 \mu \mathrm{m} \times 30 \mu \mathrm{m})$, confocal fluorescence image (B, $40 \mu \mathrm{m} \times 40 \mu \mathrm{m})$, and the emission spectrum (C) of dendrimer 2 nanofibers; NCAFM image (D, $50 \mu \mathrm{m} \times 50 \mu \mathrm{m})$, confocal fluorescence image (E, $40 \mu \mathrm{m} \times 40 \mu \mathrm{m})$, and the emission spectrum (F) of dendrimers 1 and 2 mixed (molar ratio, 5:5) nanofibers; NCAFMimage (G, $50 \mu \mathrm{m} \times 50 \mu \mathrm{m}$ ), confocal fluorescence image $(\mathrm{H}, 40 \mu \mathrm{m} \times 40 \mu \mathrm{m})$, and the emission spectrum (I) of dendrimers 1 and 2 mixed (molar ratio, 9. 1) nanofibers. All nanofibers are prepared by drop-casting a $20 \times 10^{-6} \mathrm{M}$ (total concentration) dendrimer solution in THF on a silicon surface in a saturated environment of THF : $\mathrm{H}_{2} \mathrm{O}=90.1 \mathrm{O}(\mathrm{v} x)$. The emission spectrum (excitation wavelength $488 \mathrm{~nm}$ ) of dendrimer 1 in $\mathrm{THF}$ is shown as a dotted line in (C).

excellent self-assembling properties, and there are no specific interactions between this rather small chromophore and the rigid dendrimer. Figure 5A is an AFM image of the self-assembled structures formed by dendrimer 2 on a silicon surface under a saturated mixed solvent environment ( $\mathrm{THF}: \mathrm{H}_{2} \mathrm{O}=9.1$ ). Indeed, functionalized dendrimer 2 by itself exclusively self-assembles intonanofibers as well, with dimensions similar to those of nanofibers formed from dendrimer $\mathbf{1}$ under similar experimental conditions. In contrast, no welldefined nanofibers have been visualized from functionalized dendrimer $\mathbf{3}$ with more chromophores (perylenemonoimides) attached toits periphery (vide infra). The dendrimer nanofibers formed from dendrimer 2 are fluorescent, as shown by fluorescence confocal microscopy image in Figure 5B. The sample was excited at 488 

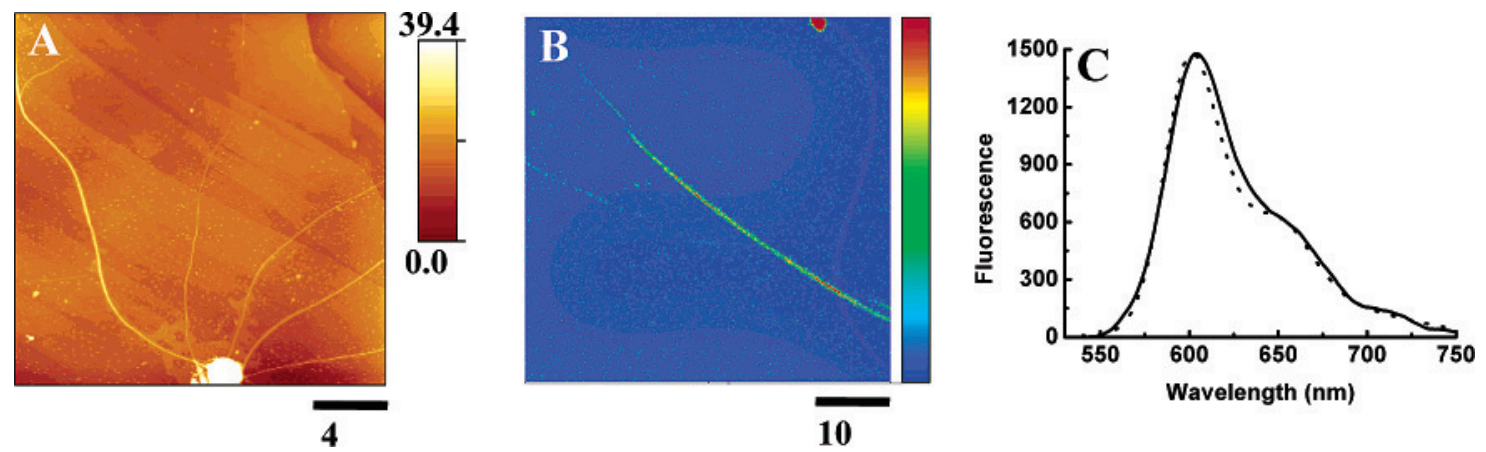

Figure 6 NCAFM image (A, $20 \mu \mathrm{m} \times 20 \mu \mathrm{m})$, confocal fluorescent image $(50 \mu \mathrm{m} \times 50 \mu \mathrm{m})$, and the emission spectrum $(\mathrm{C})$ of nanofibers prepared by drop-casting a $1 . \mathrm{O} \times 1 \mathrm{O}^{-5} \mathrm{M}$ dendrimer 4 solution in $\mathrm{CHCl}_{3}$ on a $\mathrm{HOPG}$ surface in a saturated $\mathrm{CHCl}$ atmosphere. The emission spectrum of dendrimer solution in $\mathrm{CHCl}_{3}$ is shown as a dotted line in (C).

nm using linearly polarized light, and the fluorescence images were recorded along both a parallel and a perpendicular direction. No polarization effect was observed, which indicates that the dendrimers are not anisotropically aligned over distances that are equal to or exceed the diffraction limited spot under confocal conditions $(\sim 300 \mathrm{~nm})$. Emission spectra of these nanofibers were also recorded and are shown in Figure 5C. In comparison with the fluorescence spectra of isolated dendrimers in solution, these nanofibers showed emission with a maximum around $600 \mathrm{~nm}$ (compared to the fluorescence maximum around $570 \mathrm{~nm}$ in solution), suggesting strong interactions between chromophores within these nanofibers. The fluorescence of these nanofibers is characterized by multiexponential decays with a contribution of a decay component longer than 5 ns, indicative of perylenemonoimide dimer-like emission. ${ }^{42}$ As the perylenemonoimide chromophores are linked to the periphery of dendrimers, there is quite a large possibility that they can interact.

Dendrimer $\mathbf{4}$ (structure shown in Figure 1), where a fluorescent perylenediimide function is buried deep inside the polyphenylene dendritic arms, was then employed. Decoration of perylenediimide with polyphenylene dendrons can not only increase its solubility in common organic solvents but also make its aggregation less likely. ${ }^{38}$ The formation of micrometer long nanofibers from dendrimer $\mathbf{4}$ was also expected since we have demonstrated that the interactions among polyphenylene dendritic arms lead to the formation of micrometer long polyphenylene dendrimer nanofibers. ${ }^{36 \mathrm{~b}}$ Indeed, a typical AFM image of nanofibers, together with globular aggregates, formed from dendrimer 4 is shown in Figure 6A. As expected, the self-assembled nanofibers from dendrimer $\mathbf{4}$ are fluorescent, as evidenced by the fluorescence image (Figure 6B) visualized using confocal microscopy. In contrast to the nanofibers formed by dendrimer 2 , the fluorescence spectra of those of dendrimer $\mathbf{4}$ are (almost) identical to spectra obtained in diluted solutions of 4 (Figure $6 C$ ). No red-shifted emission of these solid-state nanofibers was observed compared to the emission spectra of dendrimer $\mathbf{4}$ in solution. ${ }^{43}$ This indeed proves that the chromophores are shielded from each other in the dendrimer nanofibers as well. ${ }^{38}$ It should be pointed out that the formation of these fluorescent nanofibers is always accompanied by the formation of globular aggregates, and its formation is mainly limited to hydrophobic substrates such as HOPG and silanized mica.

(B) Self-Assembly of Mixtures of Dendrimers. Dendrimer 2 exclusively self-assembles intomicrometer long nanofibers, and by fluorescence spectroscopy, it was shown that interaction of the dendrimers within the nanofibers is observed by the dimer-like emission of the dyes. The question arises what will happen if mixtures of fluorescent and nonfluorescent dendrimers are let to self-assemble. Will this lead tothe formation of "mixed" nanofibers or other mixed self-assembled structures, or will the dendrimers phase separate? Since both nonfluorescent dendrimer $\mathbf{1}$ and fluorescent dendrimer $\mathbf{2}$, which have the same dendrimer structure, self-assemble intonanofibers under the same experimental conditions, mixtures of these dendrimers in different concentration ratios were investigated. It was observed that mixtures of dendrimers $\mathbf{1}$ and $\mathbf{2}$ exclusively lead to the formation of nanofibers (vide supra). The AFM, fluorescence images, and the emission spectra of such nanofibers formed from two mixtures with different concentration ratios are shown in Figure 5D-I. The main difference between the results based on different concentration ratios are the respective emission spectra. Upon increasing the concentration ratio of the nonfluorescent dendrimer 1 over the fluorescent dendrimer 2 , the fluorescence spectrum shifts to the blue (Figure 5C,F,I), and the spectrum in Figure 5I shows a clear vibrational fine structure which is typical for the emission of isolated perylenemonoimide chromophores. Since (1) the exclusive formation of nanofibers from the dendrimer mixtures as shown from the AFM images, (2) the predominant and rather homogeneous emission from these nanofibers, and (3) the change in the fluorescence spectrum toward monomer-like emission upon decreasing the ratio of fluorescent over nonfluorescent chromophores, we can conclude that there is homogeneous mixing of dendrimers $\mathbf{1}$ and $\mathbf{2}$ within the nanofibers over the length scale of optical resolution in confocal microscopy. Mixing dendrimers can also be used to form nanofibers even if one of the dendrimers does not form nanofibers by itself. Dendrimer 3 (structure shown in Figure 1) has the same backbone structure as dendrimer 1 but with two perylenemonoimide chromophores attached to the periphery. When dendrimer 3 solution was drop-casted on a silicon surface, nanorods instead of well-defined nanofibers were formed (Figure 7A), which indicates that the presence of two perylenemonoimide moieties interferes with the self-assembling behavior and suppresses the formation of well-defined nanofibers. However, when a mixed solution of dendrimers $\mathbf{1}$ and $\mathbf{3}$ up to a ratio of $50 \%$ of $\mathbf{3}$ was drop-casted, these dendrimers exclusively self-assemble into well-defined nanofibers. The representative AFM and fluorescent images as well as the emission spectra of nanofibers formed from the dendrimers $\mathbf{1}$ and $\mathbf{3}$ under different mixing ratios are shown in Figure 7 -I. Similar to the 

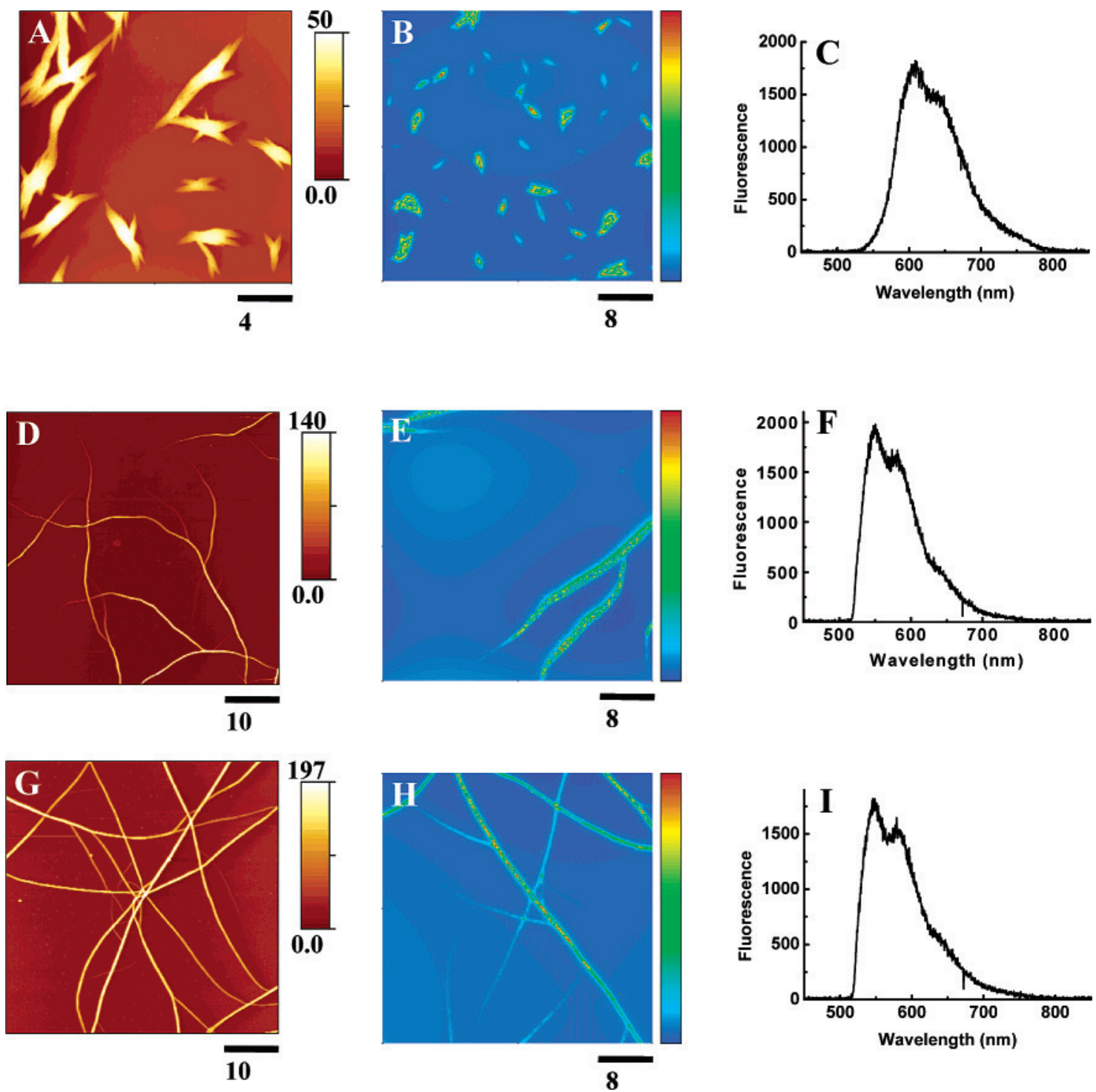

Figure 7. NCAFM image (A, $20 \mu \mathrm{m} \times 20 \mu \mathrm{m})$, confocal fluorescence image $(\mathrm{B}, 40 \mu \mathrm{m} \times 40 \mu \mathrm{m})$, and the emission spectrum (C) of dendrimer 3 nanoaggregates; NCAFM image (D, $50 \mu \mathrm{m} \times 50 \mu \mathrm{m})$, confocal fluorescence image $(\mathrm{E}, 40 \mu \mathrm{m} \times 40 \mu \mathrm{m})$, and the emission spectrum (F) of dendrimers 1 and 3 mixed (molar ratio, 5:5) nanofibers; NCAFM image $(\mathrm{G}, 50 \mu \mathrm{m} \times 50 \mu \mathrm{m})$, confocal fluorescence image $(\mathrm{H}, 40 \mu \mathrm{m} \times 40 \mu \mathrm{m})$, and the emission spectrum (I) of dendrimers 1 and 3 mixed (molar ratio, 9. 1) nanofibers. All nanofibers are prepared by drop-casting a $2 \mathrm{O} \times 1 \mathrm{O}^{-6} \mathrm{M}$ (total concentration) dendrimer solution in THF in a saturated environment of THF: $\mathrm{H}_{2} \mathrm{O}=90.1 \mathrm{O}(\mathrm{v} X)$ on a silicon surface.

mixing of dendrimer 1 and dendrimer 2 , the fluorescence emission spectrum shifts to the blue upon decreasing the relative concentration of $\mathbf{3}$, indicating homogeneous mixing and the absence of phase separation.

Mechanistic Consideration of the Polyphenylene Dendrimer Nanofiber Formation. As discussed in a previous paper, ${ }^{36 \mathrm{~b}}$ the driving force for the formation of polyphenylene dendrimer nanofibers is attributed to the $\pi-\pi$ and van der Waals interactions among dendrimer branches. Polyphenylene dendrimers are characterized as shape-persistent molecules; this welldefined 3D structure may lead tointerdigitation of parts of the polyphenylene dendrimers upon aggregation to maximize the intermolecular interactions. A dendrimer 1 tetramer model has been optimized (Figure 8), which suggests that interdigitation is favorable and could lead toa directional aggregation of dendrimer molecules. The dimer-like emission of dendrimer 2 when assembled in nanofibers points to the importance of shape-driven $\pi-\pi$ interactions stabilizing the nanofibers. The presence of two perylenemonoimide chromophores at the rim is already enough to cause steric crowding, limiting the directional growth which can be overcome by mixing with the nonsubstituted dendrimer $\mathbf{1}$.

The formation of dendrimer nanofibers could either ocaur in the dendrimer solution during the solvent evaporation or proceed directly on the surface of substrate. Even though the mechanism of the nanofiber formation is not fully understood, the visualization of dendrimer nanofiber networks (some nanofibers being superimposed on the others) and their formation on various substrates such as HOPG, silicon, glass, and mica (which implies that the formation of dendrimer nanofibers are rather independent of the surface properties of the substrate) suggests that the former mechanism is more plausible. Light scattering has demonstrated that the polyphenylene dendrimer molecules aggregate into clusters in solution upon increasing concentration. ${ }^{44}$ 


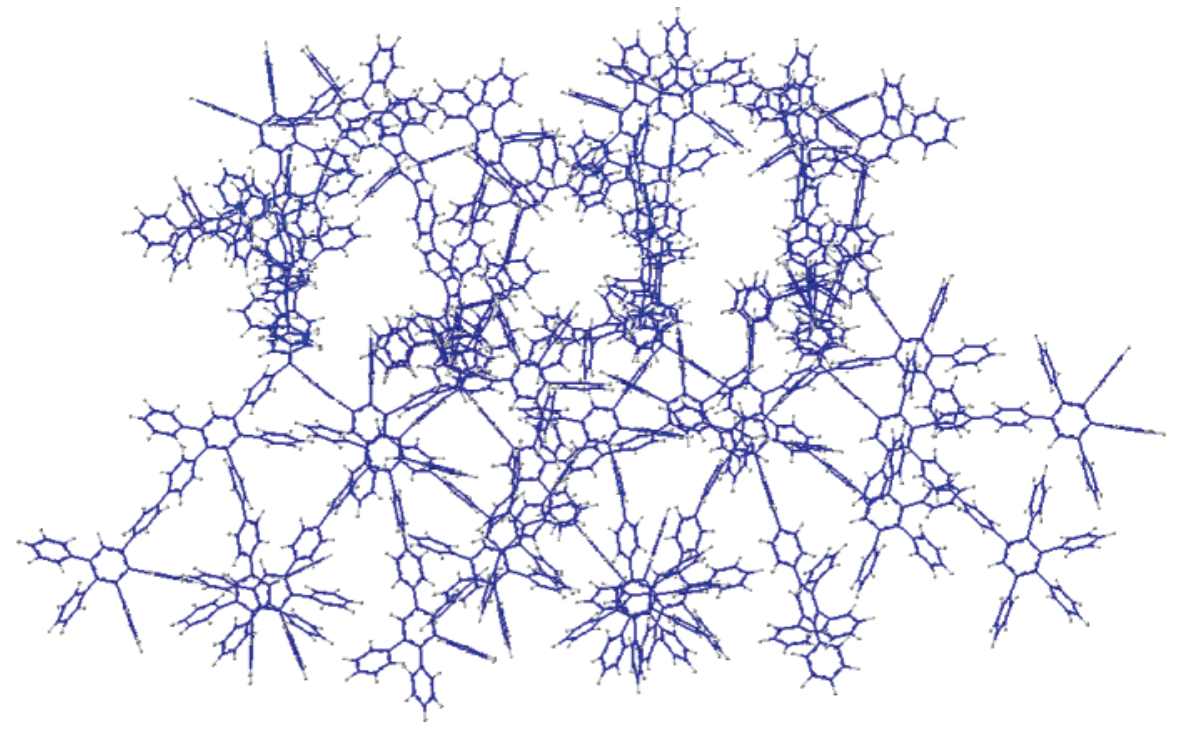

Figure 8. A tetramer model of dendrimer $\mathbf{1}$ built by the MMFF method.

\section{Conclusion}

Polyphenylene dendrimer $\mathbf{1}$ in different organic solvents exclusively self-assembles into nanofibers on various substrates upon drop-casting under a saturated solvent atmosphere. While nanofiber dusters are formed on a HOPG and silicon surface from its solution in $\mathrm{CHCl}_{3}$, dendrimer $\mathbf{1}$ self-assembles into a nanofiber network from a solution in THF on a silicon, glass, or mica surface, which distributes over the whole surface of the substrate. Addition of a small amount of water to the drop-casting THF atmosphere suppresses the nanofiber aggregation and gives rise to individual nanofibers. It has been demonstrated that the morphologies of the dendrimer $\mathbf{1}$ nanofibers can be regulated by changing solvent, substrate, and preparation method.

Fluorescent nanofibers can be prepared from a polyphenylene dendrimer with a fluorescent functional group either attached to its periphery or incorporated in its core. Polyphenylene dendrimer $\mathbf{2}$ with a perylenemonoimide chromophore attached to the periphery exclusively self-assembles into fluorescent nanofibers, which shows dimer-like emission. Polyphenylene dendrimer $\mathbf{4}$ with a perylenediimide core also self-assembles into fluorescent fibers, but the dendrimer arms shield the perylenediimide core. Mixtures of nonfluorescent dendrimer $\mathbf{1}$ and fluorescent dendrimers 2 or $\mathbf{3 l e a d}$ to the exclusive formation of fluorescent nanofibers. The emission spectrum of these nanofibers changes upon decreasing the relative concentration ratio of the fluorescent chromophore, indicating that the fluorescent dendrimers are homogeneously distributed within the nanofibers. Moreover, the nonfluorescent dendrimer 1 can act as a guest to coassemble otherwise non-fiberforming dendrimers into micrometer long nanofibers.

The dimensions of these (functional) polyphenylene dendrimer nanofibers can to a certain extent be controlled. Their formation not only is expected to add new insight intothe self-assembly parameters of dendrimers but also indicates that one can build in functionalities in these fibers. One of the challenges that remain to be solved is the stabilization of these fibers. One way to achieve this might be by introducing functionalities which could covalently link the dendrimers in the nanofibers after self-assembly.
Acknowledgment. The authors thank the DWTC through IUAP-V-OB, the FWO (Flemish Ministry of Education), the STWW through the IWT project "Molecular Nanotechnology", the German Ministry of Education and Research, and the German Science Foundation (SFB 625). The collaboration was made possible thanks to a Max-Planck Research Award. S.D.F. is a postdoctoral fellow of the "Fonds voor wetenschappelijk onderzoek-Vlaanderen" (FWO).

\section{References and Notes}

(1) Tomalia, D. A.; Naylor, A. M; Goddard, W. A., III. Angew. Chem., Int. Ed. Engl. 1990, 29, 138

(2) Newkome, G. R.; Moorefield, C. N.; Vögtle, F. Dendritic Molecules: Concepts, Synthesis, Perspectives, VCH: Weinheim, 1996

(3) Berresheim, A. J.; Müller, M.; Müllen, K. Chem. Rev. 1999, 99, 1747

(4) (a) Greyson, S. M; Fréchet, J. M. J. Chem. Rev. 2001, 101, 3819. (b) Tomalia, D. A.; Fréchet, J. M. J. J. Polym. Sci., Polym. Chem. 2002, 40, 2719.

(5) Tsukruk, V. V. Adv. Mater. 1998, 10, 253

(6) Smith, D. K.; Diederich, F. Top. Curr. Chem. 2000, 210, 183.

(7) Emrick, T.; Fréchet, J. M. J. Curr. Opin. Colloid Interface Sci. 1999, 4, 15.

(8) Tully, D. C.; Fréchet, J. M. J. Chem. Commun. 2001, 1229.

(9) Zeng, F.; Zimmerman, S. C. Chem. Rev. 1997, 97, 1681.

(10) Tomalia, D. A.; Majoros, I. In Supramolecular Polymers; Liferri, A., Ed.; Marcel Dekker: New York, 2000, p 359.

(11) Köhn, F.; Hofkens, J.; Wiesler, U.-M.; Cotlet, M; van der Auweraer, M.; Müllen, K.; De Schryver, F. C. Chem.-Eur. J. 2001, 7, 4126

(12) Watanabe, S.; Regen, S. L. J. Am. Chem. Soc. 1994, 116, 8855

(13) (a) Tsukruk, V. V.; Rinderspacher, F.; Bliznyuk, V. N. Langmuir 1997, 13, 2171. (b) Bliznyuk, V. N.; Rinderspacher, F.; Tsukruk, V. V. Polymer 1998, 39, 5249.

(14) Yoon, H. C.; Kim, H. S. Anal. Chem. 2000, 72922

(15) Khopade, A.; Caruso, F. Nano Lett. 2002, 2, 415.

(16) Wang, J.; Jia, X; Zhong, H.; Luo, Y.; Zhao, X; Cao, W.; Li, M. Chem. Mater. 2002, 14, 2854

(17) (a) Zhao, M.; Tokuhisa, H.; Crooks, R. M. Angew. Chem., Int. Ed. Engl. 1997, 36, 2596. (b) Tokuhisa, H.; Zhao, M; Baker, L. A.; Phan, V. T.; Dermody, D. L.; Garcia, M. E.; Peez, R. F.; Crooks, R. M.; Mayer, T. M. J. Am. Chem. Soc. 1998, 120 , 4492 (c) Hierlemann, A.; Campbell, J. K.; Baker, L. A.; Crooks, R. M; Ricoo, A. J. J. Am. Chem. Soc. 1998, 120, 5323 (d) Lackowshi, W. M; Campbell, J. K.; Edwards, G.; Chechik, V.; Crooks, R. M. Langmuir 1999, 15, 7632

(18) Rahman, K. M. A.; Durning, C. J.; Turro, N. J.; Tomalia, D. A. Langmuir 2000, 16, 10154 
(19) Zhang, H.; Grim, P. C. M.; Liu, D.; Vosch, T.; De Feyter, S.; Wiesler, U.-M.; Berresheim, A. J.; Müllen, K.; Van Haesendonck, C.; Vandamme, N.; DeSchryver, F. C. Langmuir 2002 18, 1801 .

(20) (a) Schlupp, M; Weil, T.; Berresheim, A. J.; Wíesler, U. M; Bargon, J.; Müllen, K. Angew. Chem., Int. Ed. 2001, 40, 4011 (b) Vossmeyer, T.; Guse, B.; Besnard, I.; Bauer, R. E.; Müllen, K.; Yasuda, A. Adv. Mater. 2002 14, 238

(21) Emmrich, E.; Franzka, S.; Schmid, G. Nano Lett. 2002, 2 1239

(22) (a) Tully, D. C.; Wilder, K.; Fréchet, J. M. J.; Trimble, A. R.; Quate, C. F. Adv. Mater. 1999, 11, 314 (b) Tully, D. C.; Trimble, A. R.; Fréchet, J. M. J. Chem. Mater. 1999, 11, 2892

(23) Li, H.; Kang, D.-J.; Blamire, M. G.; Huck, W. T. S. NanoLett 2002, 2, 347.

(24) McKendry, R.; Huck, W. T. S.; Weeks, B.; Fiorini, M.; Abell, C.; Rayment, T. Nano Lett. 2002, 2, 713

(25) Wu, X C.; Bittner, A. M. Kern, K. Langmuir 2002, 18, 4984

(26) (a) Uppuluri, S.; Swanson, D. R.; Piehler, L. T.; Li. J.; Hagnauer, G. L.; Tomalia, D. A. Adv. Mater. 2000, 12, 796. (b) Betley, T. A.; Hessler, J. A.; Mecke, A.; Manaszak Holl M. M.; Orr, B. G.; Uppuluri, S.; Tomalia, D. A.; Baker, J. R., Jr. Langmuir 2002, 18, 3127.

(27) (a) Hudson, S. D.; Jung, H. T.; Percec, V.; Cho, W. D.; Johansson, G.; Ungar, G.; Balagurusamy, V. S. K. Science 1997, 278, 449. (b) Percec, V.; Ahn, C. H.; Ungar, G.; Yeardley, D. J. P.; Möller, M. Sheiko, S. S. Nature (London) 1998, 391, 161. (c) Percec, V.; Ahn, C. H.; Cho, W. D. Jamieson, A. M.; Kim, J.; Leman, T.; Schmidt, M. Gerle, M. Möller, M. Prokhorova, S. A.; Sheiko, S. S.; Cheng, S. Z. D. Zhang, A.; Ungar, G.; Yeardley, D. J. P. J. Am. Chem. Soc 1998, 120, 8619. (d) Percec, V.; Cho, W. D.; Ungar, G. Yeardley, D. J. P. Angew. Chem., Int. Ed. 2000, 39, 1597. (e) Percec, V.; Cho, W. D.; Möller, M. Prokhorova, S. A.; Ungar, G.; Yeardley, D. J. P. J. Am. Chem. Soc. 2000, 122, 4249. (f) Yeardley, D. J. P.; Ungar, G.; Percec, V.; Holerca, M. N.; Johansson, G. J. Am. Chem. Soc. 2000, 122, 1684 (g) Percec V.; Cho, W. D.; Ungar, G. J. Am. Chem. Soc. 2000, 122, 10273 (h) Percec, V.; Cho, W. D.; Ungar, G.; Yeardley, D. J. P. J. Am. Chem. Soc. 2001, 123, 1302 (i) Percec, V.; Holerca, M N.; Uchida, S.; Cho, W. D.; Ungar, G.; Lee, Y.; Yeardley, D. J. P. Chem.-Eur. J. 2002, 8, 1106 (j) Percec, V.; Glodde, M. Bera, T. K.; Miura, Y.; Shiyanovskaya, I.; Singer, K. D.; Balagurusamy, V. S. K.; Heiney, P. A.; Schnell, I.; Rapp, A.; Spiess, H. W.; Hudson, S. D.; Duan, H. Nature (London) 2002 $19,6905$.

(28) Masuo, S.; Yoshikawa, H.; Asahi, T.; Masuhara, H. J. Phys. Chem. B 2001, 105, 2885.

(29) Schlüter, A. D.; Rabe, J. P. Angew. Chem., Int. Ed. 2000, 39, 864
(30) Müllen, K.; Wegner, G. Electronic Materials: The Oligomer Approach; Wiley-VCH: Weinheim, 1998

(31) (a) Herwig, P.; Kayser, C. W.; Müllen, K.; Spiess, H. W. Adv. Mater. 1996, \& 510. (b) Schmidt-Mende, L.; Fechtenkötter, A.; Müllen, K.; Moons, E.; Friend, R. H.; MacKenzie, J. D. Science 2001, 293, 1119.

(32) Wiesler, U. M.; Berresheim, A. J.; Morgenroth, F.; Lieser, G.; Müllen, K. Macromolecules 2001, 34, 187.

(33) Zhang, H.; Grim, P. C. M. Foubert, P.; Vosch, T.; Vanoppen, P.; Wiesler, U. M; Berresheim, A. J.; Müllen, K.; De Schryver, F. C. Langmuir 2000, 16,9009.

(34) Wind, M; Wiesler, U. M; Saalwächter, K.; Müllen, K.;Spiess, H. W. Adv. Mater. 2001, 13, 752-756.

(35) (a) Loi, S.; Wesler, U. M. Butt, H. J.; Müllen, K. Chem. Commun. 2000, 1169. (b) Loi, S.; Wiesler, U. M; Butt, H. J.; Müllen, K. Macromolecules 2001, 34, 3661. (c) Lai, S.; Butt, H. J.; Hampel, C.; Bauer, R.; Wiesler, U. M: Müllen, K. Langmuir 2002, 18, 2398

(36) (a) Liu, D.; Zhang, H.; Grim, P. C. M.; De Feyter, S.; Wiesler, U. M; Berresheim, A. J.; Müllen, K.; De Schryver, F. C. Langmuir 2002, 18, 2385. (b) Liu, D.; De Feyter, S.; Grim, P. C. M.; Vosch, T.; Grebel-Köhler, D.; Wiesler, U. M.; Berresheim, A. J.; Müllen, K.; De Schryver, F. C. Langmuir $2002,18,8283$

(37) (a) Weil, T.; Wiesler, U.-M; Herrmann, A.; Bauer, R. Hofkens, J.; DeSchryver, F. C.; Müllen, K. J. Am. Chem. Soc 2001, 123, 81O1. (b) Lor, M.; De, R.; Jordens, S.; De Belder, G.; Schweitzer, G.; Cotlet, M. Hofkens, J.; Weil, T.; Herrmann, A.; Müllen, K.; Van Der Auweraer, M.; De Schryver F. C. J. Phys. Chem. A 2002, 106, 2083-2090.

(38) Herrmann, A.; Weil, T.; Sinigersky, V.; Wiesler, U.-M; Vosch, T.; Hofkens, J.; De Schryver, F. C.; Müllen, K. Chem.-Eur. J. 2001, 7, 4844

(39) Cotlet, M.; Hofkens, J.; Habuchi, S.; Dirix, G.; Van Guyse M; Michiels, J.; Vanderleyden, J.; De Schryver, F. C. Proc. Natl. Acad. Sci. U.S.A. 2001, 98, 14398

(40) Halgren, T. A. J. Comput. Chem. 1996, 17, 490.

(41) Fondecave, R.; Wyart, F. B. Macromolecules 1998, 31, 9305.

(42) Maus, M.; Mitra, S.; Lor, M.; Hofkens, J.; Weil, T.; Herrmann, A.; Müllen, K.; De Schryver, F. C. J. Phys. Chem. A 2001 , $105,3961$.

(43) Liu, D.; De Feyter, S.; Cotlet, M.; Stefan, A.; Wiesler, U.-M; Herrmann, A.; Grebel-Koehler, D.; Qu, J.; Müllen, K.; De Schryver, F. C. Macromolecules, in press.

(44) Fytas, G. Private communication.

MAOB48573 